\title{
Presentación de un nuevo caso de adenocarcinoma de células claras uretral y su manejo quirúrgico
}

\author{
Abascal Junquera JM, Cecchini Rosell L, Martos Calvo R, Salvador Lacambra C, \\ Celma Doménech A, De Torres I*, Morote Robles J
}

Servicios de Urología y Anatomía Patológica*. Hospital Valle Hebrón. Barcelona

Actas Urol Esp. 2007;31(4):411-416

\section{RESUMEN}

\section{PRESENTACIÓN DE UN NUEVO CASO DE ADENOCARCINOMA DE CÉLULAS CLARAS URETRAL Y SU MANEJO QUIRÚRGICO}

Objetivo: presentar un caso de adenocarcinoma uretral de células claras y su manejo quirúrgico.

Material y métodos: se describe la clínica, diagnóstico, tratamiento y evolución, de este tipo de tumor. Revisión de la literatura.

Conclusión: es un tipo de tumor infrecuente que se asocia a mal pronóstico. La conformación de un reservorio con mecanismo de continencia tipo Mitrofanoff tiene su vigencia en este tipo de indicación. La cistectomía laparoscópica es una técnica realizable por grupos con cierto bagaje laparoscópico sin añadir grandes dificultades técnicas; no existe todavía un seguimiento a largo plazo como para valorar resultados oncológicos, pero sí se vislumbran ciertas ventajas funcionales.

Palabras clave: Adenocarcinoma uretral de células claras. Cistectomía radical laparoscópica. Mitrofanoff.

\section{ABSTRACT}

\section{PRESENTATION OF A NEW CASE OF PRIMARY CLEAR CELL ADENOCARCINOMA} OF THE URETHRA AND ITS SURGICAL MANAGEMENT

Objective: To present a new case of a primary clear cell adenocarcinoma of the urethra and its surgical management.

Material and methods: We describe the clinical, diagnosis, treatment and development of this kind of tumor. Review of the literature.

Conclusions: It is an unusual type of cancer associated with poor prognosis. Currently the construction of a continent urinary diversion using the Mitrofanoff principle has many indications as our case. Laparoscopic radical cystectomy can be done by experienced groups without adding much more technical difficulties; there are no long-term oncological outcome data but we believe in some functional advantages.

Keywords: Clear cell adenocarcinoma of the urethra. Laparoscopic radical cystectomy. Mitrofanoff.

Los tumores primarios de uretra son neoplasias poco frecuentes en el día a día urológico; el adenocarcinoma uretral de células claras representa una variante excepcional.

A continuación describimos un nuevo caso de este tipo de tumor y su manejo quirúrgico. Se realizó una cistectomía laparoscópica, técnica que cada vez va ganando más peso en la urología actual y posteriormente se confeccionó un reservorio continente aplicando el principio de Mitrofanoff.

\section{CASO CLÍNICO}

Se trata de una mujer de 41 años fumadora de un paquete diario y sin otros antecedentes personales de interés salvo un hermano que había sido intervenido por RTU un año antes de un tumor vesical superficial. 
La paciente consulta a un internista de nuestro centro por un cuadro de 6 meses de evolución de polaquiuria, disuria y tenesmo vesical, sin hematuria ni incontinencia urinaria, acompañado de astenia y anorexia. Se solicita un primer urocultivo que resulta negativo y tras varias semanas de tratamiento con fitoterapia y antiinflamatorios sin ninguna mejoría clínica, se objetiva una leucocituria estéril en el sedimento urinario; el urocultivo persiste negativo. Se solicita un BK en orina que también resulta negativo y una citología urinaria que informa de sospecha de carcinoma transicional.

En la analítica sanguínea no se demuestran alteraciones significativas y en la exploración física llama la atención en el tacto vaginal un endurecimiento generalizado de la cara anterior vaginal. En este momento se solicita una ecografia y una TAC y se remite a nuestras consultas externas para valoración urológica.

En la TAC se visualiza una masa endovesical sobre todo a expensas de la cara posterior sin demostrarse claramente plano de separación con el útero (Fig. 1).

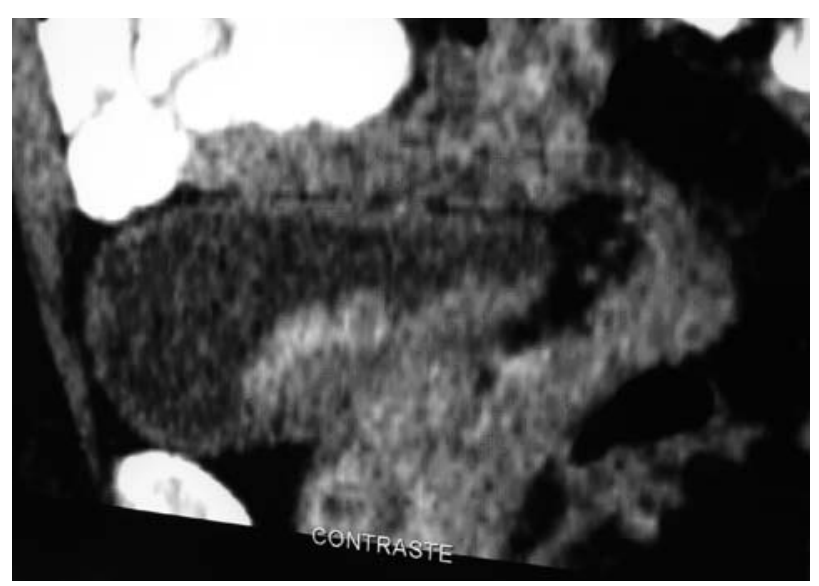

FIGURA 1. Corte longitudinal del TAC en el que se aprecia masa endovesical a expensas de la cara posterior sin apreciarse un claro plano de separación con el útero.

Se decide en este momento la revisión endoscópica vesical demostrándose una masa de base amplia y aspecto y consistencia sólida, que ocupaba prácticamente toda la uretra y el suelo vesical. Los meatos ureterales estaban indemnes. La uretra estaba totalmente desestructurada como una cavidad anfractuosa y existían signos de vejiga de lucha. Se practicó una resección parcial con intención biópsica.
El resultado anatomopatológico informó de adenocarcinoma uretral de células claras con afectación de cuello vesical (pT3).

Se planteó a la paciente una exanteración pélvica anterior y las dos posibilidades de derivación urinaria, incontinente tipo Bricker ó reservorio continente, decidiéndose realizar este último conjuntamente con la paciente. La cirugía se desarrolló en 3 tiempos: en primer lugar, un tiempo laparoscópico, realizándose la cistectomía, histerectomía, anexectomía izquierda (se conservó el ovario derecho por la edad de la paciente, y posteriormente se fijó a la pared abdominal para evitar una posible torsión en el futuro); en segundo lugar, un tiempo vaginal en el que se realizó la uretrectomía amplia; y por último, el tiempo intestinal en el que se confeccionó mediante una laparotomía infraumbilical, un reservorio tipo Padovana con mecanismo de continencia aplicando la teoría de Mitrofanoff (Fig. 2). Asimismo durante la cirugía abierta se aprovechó para realizar la linfadenectomía ilio-obturatriz bilateral, ya que durante el tiempo laparoscópico se objetivaron varias adenopatías de gran tamaño y adheridas a vasos iliacos, que desaconsejaron su extirpación en ese momento.

Para la cistectomía laparoscópica colocamos 5 trócares transperitonealmente con la paciente en posición de Trendelemburg forzado, tres de ellos de 10-12 mm en ambas fosas iliacas y supraumbilicalmente, y dos, de $5 \mathrm{~mm}$ en flanco izquierdo

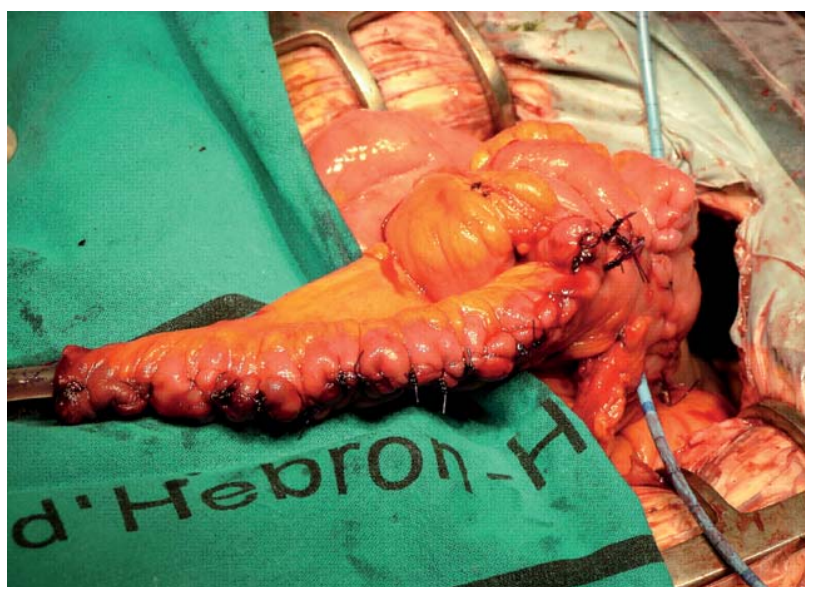

FIGURA 2. Neovejiga tipo Padouana y mecanismo de continencia tipo Mitrofanoff utilizando ileon terminal que se encuentra tutorizado por sonda rigida del calibre ch 18 . Se aprecian catéteres ureterales tutorizando ambos uréteres $y$ exteriorizados por contrabertura. 
y a nivel suprapúbico, aunque existen también otras posibilidades. Se incide en la hoja peritoneal posterior hasta los vasos iliacos y se identifican ambos uréteres; disección de los espacios laterales hasta la fascia endopélvica; se accede al espacio de Retzius previa disección del uraco y los ligamentos umbilicales laterales; coagulación de los pedículos vésico-uterinos con ligasure; se disecan ambos uréteres distalmente hasta su entrada en vejiga y luego se clipan; posteriormente en este caso se realizó una disección parcial del cuello vesical que se completó durante el tiempo vaginal.

El tiempo vaginal consistió en una exéresis amplia del meato uretral que englobó buena parte de la pared vaginal anterior.

Se aisló una asa ileal de unos $40 \mathrm{~cm}$, realizándose una destubularización de los dos tercios proximales y una reconstrucción esferoidal de éstos, dónde se abocaron ambos uréteres; el tercio distal sirvió para construir el mecanismo de continencia utilizando un segmento de ileon de aproximadamente 10-12 cm, que se resecó longitudinalmente hasta reducir su diámetro a la mitad, estando en todo momento tutorizado por una sonda rígida (ch 18). Posteriormente este asa se abocó a la fosa iliaca derecha, previa fijación a la pared abdominal para evitar angulaciones y posibles complicaciones a la hora de realizar los autocateterismos en el futuro.

La duración aproximada de la cirugía fue de 5 horas, con un sangrado de $500 \mathrm{ml}$. La paciente recuperó el tránsito intestinal al tercer día, y fue dada de alta a la semana de la intervención, siendo portadora de una sonda que tutorizaba el reservorio. En su domicilio se ha ido realizando lavados diarios del reservorio con suero fisiológico para evitar la formación de acúmulos de moco intestinal. La sonda se retiró a las 3 semanas y desde entonces la paciente se autocateteriza cada 3-4 horas con una sonda de menor calibre que la que se utilizó durante la cirugía.

El resultado anatomopatológico confirmó el origen uretral del tumor (adenocarcinoma de células claras), esta vez demostrando mayor afectación vesical (trígono, pared lateral derecha) y de la cara anterior vaginal (Fig. 3); de los 23 ganglios linfáticos que se enviaron a analizar, 16 resultaron positivos, ninguno de ellos mayor de $5 \mathrm{~cm}$, por lo tanto se estadió como un pT4N2.

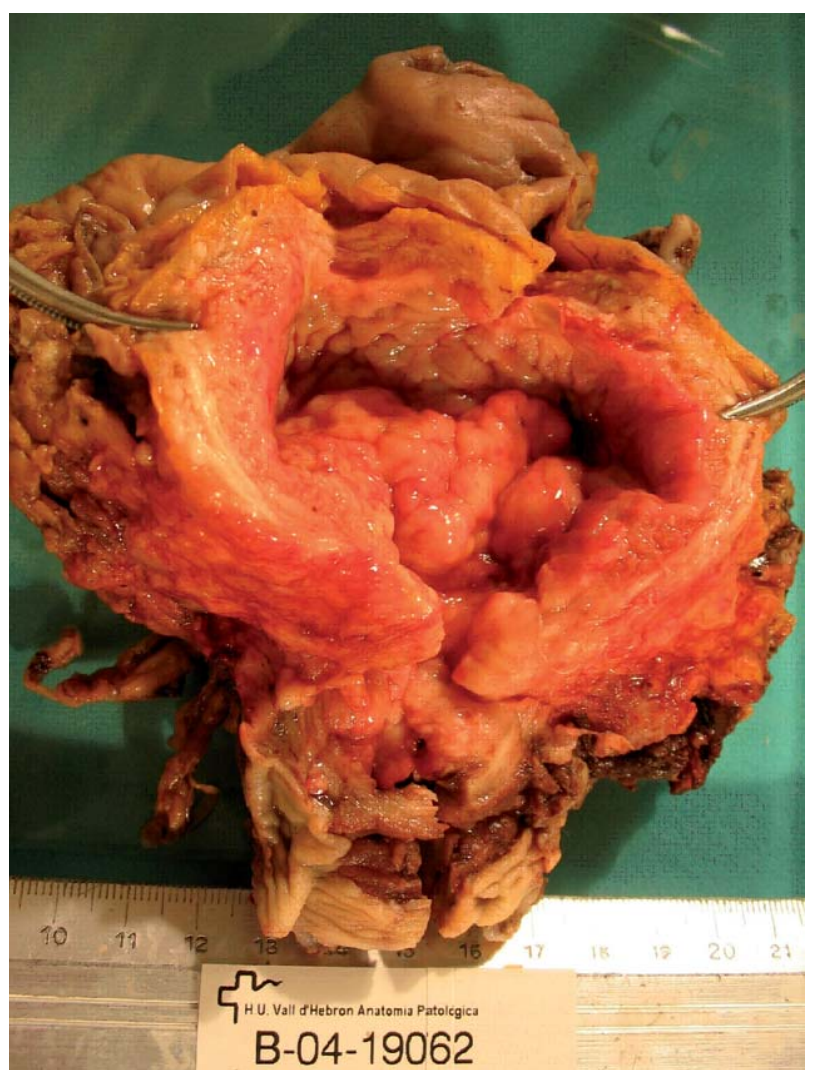

FIGURA 3. Aspecto macroscópico de la pieza quirúrgica. Afectación de trigono y pared lateral derecha vesical y cara anterior vaginal.

Microscópicamente se describió un intenso infiltrado inflamatorio linfoplasmocitario y un patrón mixto con zonas glandulares y otras sólidas, constituido por células claras (es decir, gran citoplasma que no se tiñe) y abundantes células en tachuela. Se realizó tinción con CA-125 que resultó positiva (Fig. 4) y de PSA que fue negativa.

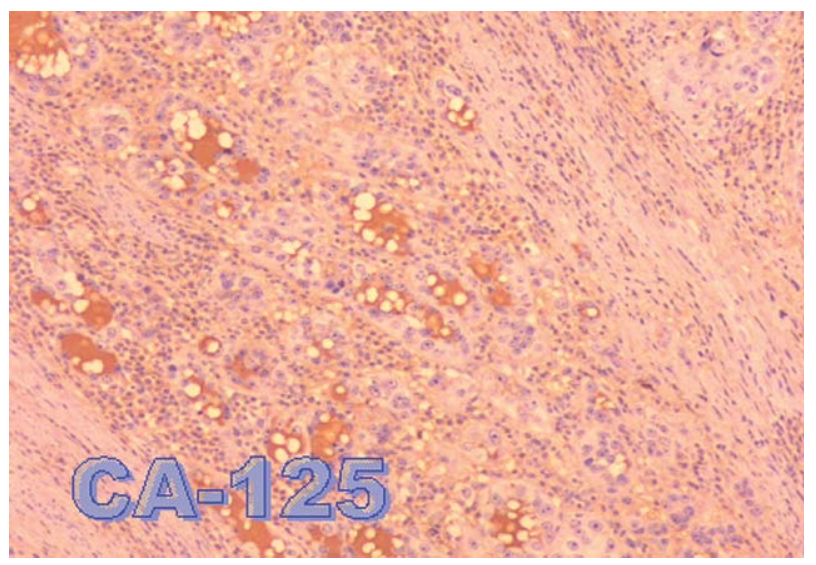

FIGURA 4. Tinción positiva para CA-125. 
La paciente ha recibido cinco ciclos de quimioterapia (carboplatino y taxol) y radioterapia pélvica.

A los 6 meses de la cirugía la paciente se encuentra continente realizándose autocateterismos cada 4 horas al día. Se ha practicado un TAC de control en el que se objetivan varias adenopatías a nivel retroperitoneal, por lo que la paciente está pendiente de un nuevo ciclo de tratamiento adyuvante con quimioterapia de segunda línea.

\section{DISCUSIÓN}

El tumor uretral primario es un tumor poco frecuente, siendo el único del tracto urinario predominante en mujeres (4-5 $\left.\bigcirc-10^{7}\right)$. Se desarrolla sobretodo durante la sexta década ${ }^{1}$.

Histológicamente predomina la variante epidermoide (70\%). El 20\% serían de estirpe transicional y el resto, incluiría los adenocarcinomas, melanomas, sarcomas, etc.

El diagnóstico clínico es inespecífico. Puede debutar en forma de hematuria y/ó uretrorragia, síndrome miccional, infecciones urinarias de repetición. El diagnóstico radiológico viene determinado por el síntoma de alerta y nos podemos ayudar de una cistoscopia y uretroscopia, una cistografía miccional y uretrografía retrógrada, TAC y RMN. En general se prefiere la resonancia magnética frente al scanner para analizar las partes blandas del área pélvica ${ }^{1}$.

La extensión linfática de este tipo de tumores difiere según su localización. Los tumores de uretra anterior se extienden hacia los ganglios inguinales, mientras que los de uretra posterior ocupan los ganglios pélvicos. En este sentido, es importante destacar el alto porcentaje de malignidad (80-100\%) de las adenopatías inguinales palpables, a diferencia de las neoplasias de pene, dónde se describe un componente inflamatorio-reactivo hasta en la mitad de los $\operatorname{casos}^{1}$.

Los tumores de uretra se caracterizan por su gran agresividad local y sólo desarrollan metástasis viscerales en alrededor del 15\% de los casos $^{1}$.

Existen grupos que describen el tratamiento de lesiones circunscritas y de pequeño tamaño con cirugía parcial incluso con braquiterapia, aunque en la mayor parte de los casos se aboca hacia una cirugía radical. No existe un estándar en cuanto a tratamiento adyuvante. Se han descrito series tanto con radioterapia como con quimioterapia ${ }^{2}$.

El pronóstico varía en función de la extensión tumoral (tamaño) y de la histología. De hecho, en la mayor serie que recoge la literatura sobre tumores uretrales en la que se realiza un análisis multivariable de factores pronósticos, sólo la histología y el tamaño del tumor resultaron estadísticamente significativos. En concreto, en esta serie se describen 5 adenocarcinomas de células claras, de los cuales todos eran mayores de $4 \mathrm{~cm}$ y ninguno sobrevivió a los 5 años de seguimiento $^{2}$.

El adenocarcinoma de células claras uretral engloba menos del 10\% de los tumores uretrales primarios junto con otros tumores poco frecuentes (melanomas, sarcomas, etc.). Existen menos de 50 casos descritos en la literatura mundial. Afecta sobretodo a mujeres (85\%) y hasta en la mitad de los casos se desarrolla en el contexto de un divertículo uretral $^{3}$.

El origen embriológico de este tipo de tumores sigue siendo controvertido. En la literatura antigua se describía este tipo de lesiones con un origen mesonéfrico, incluso se hablaba del adenoma mesonéfrico como una lesión preneoplásica de este tipo de tumor. En la actualidad se encuentra más aceptada la teoría del origen mulleriano, puesto que el adenocarcinoma de cél. claras se tiñe en la mayoría de los casos con un antigeno frecuentemente expresado en tumores ginecológicos con establecido origen mulleriano, el CA-125. También se ha descrito la posibilidad de un origen en las glándulas de Skene, por la tinción positiva en algunos casos para PSA. En una revisión reciente de 13 casos de adenocarcinoma uretral de cél. claras en ninguno de los tumores la tinción para PSA fue positiva, por lo que es un argumento en contra de esta teoría ${ }^{3-4}$.

Microscópicamente se caracterizan por un patrón mixto, túbulo-quístico ó glandular, con células en forma de tachuela, abundante citoplasma claro (que no se tiñe) y gran número de mitosis (a diferencia del adenoma mesonéfrico) ${ }^{3,4}$.

Podría determinar cierta dificultad a la hora de diferenciarlo de una metástasis uretral secundaria a un adenocarcinoma de células cla- 
ras renal, pero esta situación es excepcional y además, existen ciertas peculiaridades microscópicas que nos ayudarían a diferenciarlos ${ }^{3,4}$.

El mecanismo de continencia tipo Mitrofanoff ó principio de la válvula de lengüeta fue descrito por este urólogo francés en el año 1980. Existen distintas indicaciones tanto en patología benigna como maligna (extrofia vesical, vejiga neurógena, tumores del área pélvica que requieran la extirpación de la uretra) ${ }^{5}$ y su uso es frecuente en la urología pediátrica.

Se trata de conformar un conducto flexible y de pequeño diámetro, submucoso, por lo que se produce una compresión de su luz contra la pared rígida del depósito, con lo que se conseguirá la continencia deseada. Durante la cirugía el conducto se mantiene tutorizado por una sonda rígida de un calibre amplio. El trayecto del conducto ha de ser liso y sin ángulos y posteriormente, se fija a la pared abdominal para evitar dificultades posteriores en los autocateterismos ${ }^{5}$.

La técnica original se describió utilizando el apéndice como conducto, abocado al ombligo. Posteriormente, y dado que un gran número de pacientes en el momento de la cirugía se encontraban apendicectomizados, ó el apéndice no tenía la longitud suficiente, se han descrito variantes utilizando ileon, detrusor, trompa de Falopio, uréter y piel de prepucio ${ }^{6,7}$.

$\mathrm{El}$ reservorio se mantiene sondado durante 34 semanas y posteriormente antes de la retirada se puede rellenar el reservorio con contraste para descartar la presencia de fugas urinarias. Las primeras semanas se recomienda la realización de autocateterismos intermitentes entre periodos breves de tiempo (cada 3-4 horas durante el día y cada 6 horas durante la noche). También se recomienda para los autocateterismos la utilización de una sonda de menor calibre que el que se utilizó durante la cirugía como tutor y una buena lubricación ${ }^{5}$.

Los resultados funcionales de esta técnica a largo plazo señalan tasas de continencia por encima del $85 \%$. La principal complicación que es la estenosis del estoma, está descrita hasta en un $20 \%$ de los pacientes y parece ser que se da con mayor frecuencia cuando el conducto utilizado no es el apéndice. La formación de litiasis dentro del reservorio se describe hasta en el 30\% de los casos ${ }^{8}$.
Desde que en 1992 Parra R y col. describiesen la primera cistectomía simple laparoscópica, distintos grupos han ido describiendo variaciones en la técnica tanto clínica como experimentalmente, hasta que Gill I et al. publicasen la primera cistoprostatectomía radical y derivación urinaria totalmente intracorpórea en el año $2000^{9}$.

Las principales variantes de esta técnica son: la pura, totalmente intracorpórea en la que tanto la cistectomía como la derivación urinaria se realizan laparoscópicamente; la asistida, en la que se realiza un primer tiempo laparoscópico para la cistectomía y posteriormente, mediante una laparotomía infraumbilical se desarrolla el tiempo intestinal; la mano-asistida y la asistida mediante robot $^{9,10}$.

Se trata de una técnica que requiere cierto bagaje en cirugía laparoscópica pero que comparada con la prostatectomía radical laparoscópica no añade gran dificultad; además se asemeja en prácticamente todos los pasos a la cirugía abierta.

En la actualidad no existen en la literatura series con un seguimiento suficiente como para comparar resultados oncológicos entre la técnica abierta y la laparoscópica, pero sí que se parecen vislumbrar una serie de ventajas a nivel de resultados funcionales a favor de la técnica laparoscópica, entre los que destacan: una menor pérdida sanguínea, menor dolor postoperatorio y por tanto, menor necesidad de analgesia postoperatoria, estancia hospitalaria más corta, y una recuperación del tránsito intestinal más rápida. Como inconvenientes cabe señalar el mayor tiempo operatorio, mayor coste y la necesidad de cierta experiencia en laparoscopia ${ }^{11}$.

Creemos que se trata de una técnica que cada vez cuenta con más adeptos dentro del mundo urológico, que no entraña mayor dificultad que la otra gran cirugía pélvica laparoscópica urológica, la prostatectomía radical, y que el tiempo decidirá su lugar en la urología diaria.

\section{REFERENCIAS}

1. Mauroy B. Uretra femenina normal y patológica. Enciclopedia Médico-quirúrgica; 18-400-A-10. Editores Abecassis R, Baron JC, Belenfant X. París, 1998.

2. Grigsby P. Carcinoma of the urethra in women. Int $J$ Radiat Oncol Biol Phys. 1998;41(3):535-541. 
3. Oliva E, Young RH. Clear cell adenocarcinoma of the urethra: a clinicopathologic analysis of 19 cases. Mod Pathol. 1996;9(5):513-520.

4. Drew PA, Murphy WM, Civantos F, Speights VO. The histogenesis of clear cell adenocarcinoma of the lower urinary tract: case series and review of the literature. Hum Pathol. 1996;27:248-252.

5. Mitrofanoff P. Cystostomie continent trans-appendiculaire dans le traitement des vessies neurologiques. Chir Ped. 1980;21:297-305.

6. Monti PR, Lara RC, Dutra MA, de Carvalho JR. New techniques for construction of efferent conduits based on the mitrofanoff principle. Urology. 1997;49:112-115.

7. Woodhouse CR, Macneily AE. The Mitrofanoff principle: expanding upon a versatile technique. BJU. 1994;74:447 453.

8. Liard A, Seguier-Lipszyc E, Mathiot A, Mitrofanoff P. The Mitrofanoff procedure: 20 years later. J Urol. 2001;165:2394 2398.
9. Hrouda D, Abdeyoju A and Gill I. Laparoscopic radical cystectomy and urinary diversion: fad or future? BJU Int. 2004 Sep;94(4):501-505.

10. Moinzadeh A and Gill I. Laparoscopic radical cystectomy with urinary diversion. Curr Opin Urol. 2004;14:83-87.

11. Basillote JB, Abdelshehid C, Ahlering TE, Shanberg AM. Laparoscopic assisted radical cystectomy with ileal neobladder: a comparison with open approach. J Urol. 2004; 172:489-493.

Correspondencia: Dr. J.M ${ }^{\mathrm{a}}$ Abascal Junquera Servicio de Urologia. Hospital Vall d’Hebron Passeig Vall d`Hebron, 119-129. 08035 Barcelona Tel.: 606956077

E-mail autor: josuvargas@hotmail.com

Información artículo: Nota clínica

Trabajo recibido: enero 2006

Trabajo aceptado: marzo 2006 